\title{
Correlation of Indoor Air Quality with Working Performance in Office Building
}

\author{
Ismail Abdul Rahman ${ }^{1}$, Jouvan Chandra Pratama Putra ${ }^{1} \&$ Sasitharan Nagapan ${ }^{1}$ \\ ${ }^{1}$ Faculty of Civil and Environmental Engineering, Universiti Tun Hussein Onn Malaysia, Malaysia \\ Correspondence: Jouvan Chandra Pratama Putra, Faculty of Civil and Environmental Engineering, Universiti \\ Tun Hussein Onn Malaysia, Malaysia. E-mail: jouvanchandra@gmail.com
}

\author{
Received: June 18, $2014 \quad$ Accepted: June 26, $2014 \quad$ Online Published: October 23, 2014 \\ doi:10.5539/mas.v8n6p153 URL: http://dx.doi.org/10.5539/mas.v8n6p153
}

\begin{abstract}
In Malaysia, most of office building utilizes mechanical ventilation system to maintain its indoor air quality. However, if the mechanical ventilation system is not properly installed and maintained, it will contribute to poor indoor air quality which leads to decrease the productivity of office workers. This study assessed the correlation of indoor air quality toward working performance at office building in Universiti Tun Hussein Onn Malaysia using questionnaire survey. The findings revealed that the office can be categorized as sick building syndrome with the highest symptom is lethargy as marked by $75 \%$ of the office workers. Since most of office workers are unauthorised to adjust temperature and air velocity of the air-conditioning system, this leads to the dissatisfaction toward indoor air quality where $40 \%$ of the respondents are dissatisfied with temperature and air velocity. Ultimately, this study has successfully indicated that temperature has the strongest correlation with working performance as indicated by spearman correlation value of 0.648 .
\end{abstract}

Keywords: indoor air quality, sick building syndrome, occupant satisfaction, working perfomance, rank spearman

\section{Introduction}

Office worker productivity is one of the critical factors that made a company to survive in a tight industry competition (Mahbob et al., 2011). One of approaches to enhance productivity is by maintaining good Indoor Air Quality (IAQ) of the office building where a lot time is spent by the office staffs (Kosonen \& Tan, 2004). In Malaysia, most of the office building utilizes mechanical ventilation system to maintain good IAQ by distributing indoor air adequately (Kamaruzzaman \& Sabrani, 2011; WHO, 2009). However, if the mechanical ventilation system is not properly installed and maintained, it will provides poor indoor air that can decrease the productivity of the office staffs (Melikov \& Kaczmarczyk, 2012). Poor IAQ is characterized by the occurrence of Sick Building Syndrome (SBS) (Joshi, 2008; Sulaiman, 2011). SBS is defined as a situation where building occupants experience acute health related to the time spent indoor (Joshi, 2008) and without a clear cause reported by building's occupants (Israeli \& Pardo, 2011). An office building is categorized as sick building if at least $20 \%$ of the occupants show symptoms of illness without clear cause and the symptom will disappear once the occupant leave the building (Hansen, 1991). Likely, the staffs who suffers SBS symptoms will take sick leave and if this regularly happened, it will decreases the productivity of office staffs which finally decrease the company productivity (Kamaruzzaman \& Sabrani, 2011).

Productivity of the office staffs can be determined by assessing their working performance (Mahbob et al., 2011) which is defined as actions that contribute to organizational goals and that are under the individual's control (Rotundo, 2002). Many researchers had investigated working performance of office worker which was influenced of IAQ through real experiment in office (Antikainen et al., 2008; Federspiel et al., 2002; Kamaruzzaman \& Sabrani, 2011; Khalil \& Husin, 2000; Mahbob et al., 2011; Fisk et al., 2002; Wyon, 2004) and laboratory experiment (Antikainen et al., 2008; Kosonen \& Tan, 2004; Wargocki \& Wyon, 2000; Wyon, 2004). According to Wargocki et al (2000), real study by using office building indicated the best approach for assessing working performance of office worker as compared to laboratory experiment. However, the current standard and guideline to assess the indoor environment mostly developed from the laboratory experiment by using environmental chamber conditions without consideration of modern office variables (Jones, 2002; Linden et al., 2006), and this is could affect to the discrepancy results between perception of office worker and guideline. In 
assessing the working performance, questionnaire survey is adopted where the questions asked are regarding IAQ parameters which include temperature (Federspiel et al., 2002; Kamaruzzaman \& Sabrani, 2011; Khalil \& Husin, 2000; Mahbob et al., 2011; Wargocki \& Wyon, 2000; Fisk et al, 2002; Wyon, 2004), air velocity (Federspiel et al., 2002; Khalil \& Husin, 2000; Kosonen \& Tan, 2004; Mahbob et al., 2011; Wargocki \& Wyon, 2000; Fisk et al, 2002; Wyon, 2004), relative humidity (Federspiel et al., 2002; Wargocki \& Wyon, 2000; Fisk et al., 2002; Wyon, 2004), $\mathrm{CO}$ (Mahbob et al., 2011), $\mathrm{CO}_{2}$ (Federspiel et al., 2002; Khalil \& Husin, 2000; Kosonen \& Tan, 2004; Mahbob et al., 2011; Fisk et al., 2002), occupant satisfaction (Kamaruzzaman \& Sabrani, 2011; Khalil \& Husin, 2000; Kosonen \& Tan, 2004; Mahbob et al., 2011; Wyon, 2004), Radon (Mahbob et al., 2011) and Sulphur Dioxide (Mahbob et al., 2011). Thus, this study is designed to determine a correlation of IAQ with working performance based on occupants' perception in a selected office building.

\section{Methods}

In this study, a set of questionnaire was designed to assess the likeliness of SBS presence and relationship of IAQ with working performance. Thus, the questionnaire consisted two parts where the first part regarding the SBS presence and the second part about occupants' satisfaction on IAQ related to working performance. A 5-point Likert scale was used to this questionnaire to interpret the perception of office workers regarding SBS symptoms presence and also IAQ's satisfaction with working performance as in table 1.

Table 1. Scale used to measure occupants' perceptions

\begin{tabular}{llll}
\hline Scale & $\begin{array}{l}\text { Degreeof } \\
\text { Occurrence }\end{array}$ & $\begin{array}{l}\text { Degreeof } \\
\text { satisfaction }\end{array}$ & $\begin{array}{l}\text { Degree of Working } \\
\text { Performance }\end{array}$ \\
\hline 1 & Never & Very dissatisfied & Very interfere \\
2 & Very rarely & Dissatisfied & Interfere \\
3 & Rarely & Neutral & Neutral \\
4 & Frequently & Satisfied & Enhances \\
5 & Very Frequently & Very satisfied & Very enhances \\
\hline
\end{tabular}

Once the data from questionnaire surveys collected, correlation test is used for assess the strength of association between IAQ and working performance. As data collected in this study is nonparametric and ordinal variables, the proper methods for examining the relationship between pairs of variables is by using Spearman's correlation (Bryman \& Cramer, 2002). The correlation value coefficient (" $\rho$ ") ranges from -1.0 to +1.0 . The closer $\rho$ is to +1.0 or -1.0 , the more closely two variables are related. The value of $\rho$ close to 1 implies that there is strong positive linear relationship between the two variables while the value of $\rho$ close to -1 is a strong negative linear relationship between two variables (Daud et al., 2009). Ideally, the correlation coefficient value of \pm 1 is said to be a perfect correlation. Assume correlation coefficient value lies between \pm 0.5 and \pm 1 , then it is said to be a high degree of correlation and for the correlation coefficient value lies between \pm 0.3 and \pm 0.5 , then it is said to be moderate degree of correlation. If correlation coefficient value lies between \pm 0.1 and \pm 0.3 then it is said to be a low degree of correlation and suppose correlation coefficient value lies around zero, then there is no correlation (Cohen, 1988).

\section{Results and Discussion}

A total of 20 sets of questionnaire were distributed to the office workers of the Office for Research, Innovation, Commercialization and Consultancy Management (ORRIC) office building in Universiti Tun Hussein Onn Malaysia (UTHM). All the distributed questionnaires are received back. The data from the questionnaires were analysed using SPSS v.17.0 and the findings are presented and discussed in the following subsection.

\subsection{Demographic of Office Workers}

Out of 20 workers participated in this survey, 7 are males and 13 are females. Besides, in-term of their academic qualification, $60 \%$ of the office workers hold diploma and $40 \%$ with bachelor degree. Thus, the office workers in this office building are quite competent and capable to participate in the survey. For assessing the working performance of office worker, many of researchers have suggested the reliable activities to measure it such as, typing work, input database, and reading (Federspiel et al., 2002; Jones, 2002; Wargocki \& Wyon, 2000). For this survey, the activities are categorized into two types of works that are managerial and clerical. The survey found $75 \%$ of the workers doing clerical works as compared to $25 \%$ are doing managerial activities as in figure 1. 


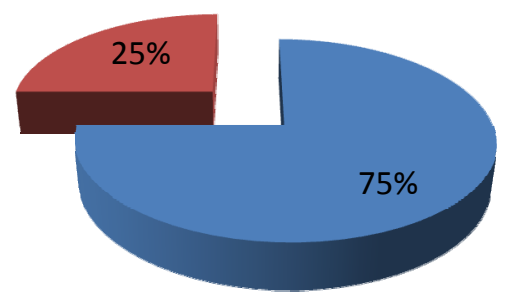

Secretarial or

clerical

- Managerial

Figure 1. Job category

On other hand, the duration of staying/working in the office building is very important to determine whether the workers' perception in describing IAQ and its effect to working performance is correct. The demography of workers' duration staying/working in the office building is presented as in figure 2 .

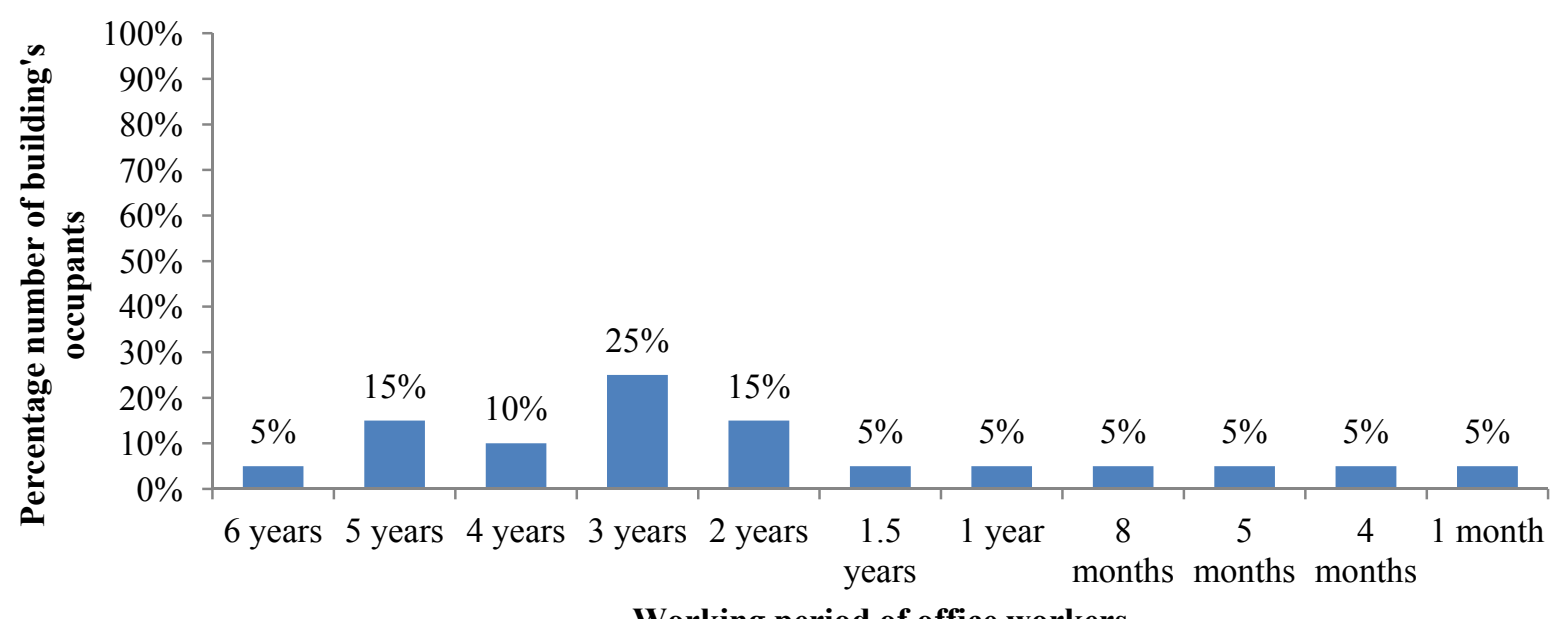

Working period of office workers

Figure 2. The working period of office workers

The highest percentage of workers working in the office is $25 \%$ which means majority of the workers had been working for 3 years in the office. However, the least percentage is $5 \%$ for the workers who had been working for the periods of 1 month, 4 months, 5 months, 8 months, 1 year, 1.5 years and 6 years respectively.

\subsection{Likeliness of SBS Presence}

To determine the likeliness of SBS presence amongst the office workers, they are asked about their healthy condition which related to SBS presence in past two weeks. The workers were requested to rate level of occurrences on the list of symptoms regarding SBS provided to them in the questionnaire survey. However, frequently level is considered in pre-determining the likeliness of SBS presence and the results of the survey are summarized in table 2 . 
Table 2. Likeliness of SBS symptoms in the office building

\begin{tabular}{llll}
\hline $\begin{array}{l}\text { Number } \\
\text { of } \\
\text { Symptom }\end{array}$ & Types of SBS Symptoms & $\begin{array}{l}\text { No.of occupants } \\
\text { experiencing } \\
\text { the symptoms }\end{array}$ & \% \\
\hline 1 & Dry Eyes & 3 & 15 \\
2 & Blocked Nose & 5 & 25 \\
3 & Sore Throat & 8 & 40 \\
4 & Headache & 11 & 55 \\
5 & Lethargy & 17 & 85 \\
6 & Watering Eyes & 3 & 15 \\
7 & Running Nose & 6 & 30 \\
8 & Flu Symptoms & 10 & 50 \\
9 & Breathing Tightness & 5 & 25 \\
10 & Itching & 10 & 50 \\
11 & Allergy & 7 & 35 \\
12 & Cough & 10 & 50 \\
13 & Nausea & 1 & 5 \\
14 & Asthma & 2 & 10 \\
15 & Muscle Pain & 5 & 25 \\
16 & Fatigue & 6 & 30 \\
17 & Difficulties in concentrating & 4 & 20 \\
\hline
\end{tabular}

From the table 2 , only 4 types of SBS symptoms are below $20 \%$ of occupants are experiencing the symptoms while the other 13 types of symptoms are experienced by $20 \%$ and more of the occupants. Thus, we can indicate that SBS symptoms did presence in the office building.

In order to determine which symptoms are contributing to the sick building, Hansen (1991) stated that an office building can be categorized as sick building if at least $20 \%$ of building's occupant had SBS symptoms in which these symptoms will disappear after they leave the office building. Subsequently, the building's occupants were asked which symptoms disappeared after leaving the office regarding based on the same list of the symptoms. The results of this survey are as in table 3 .

Table 3. Justification of SBS symptoms that disappeared after leaving the office

\begin{tabular}{llcc}
\hline $\begin{array}{l}\text { Number } \\
\text { of } \\
\text { Symptom }\end{array}$ & Types of SBS Symptoms & $\begin{array}{c}\text { No. of occupants who } \\
\text { not experiencing the } \\
\text { symptoms after left } \\
\text { the building }\end{array}$ & \% \\
\hline 1 & Sore Throat & 5 & 25 \\
2 & Headache & 7 & 35 \\
3 & Lethargy & 15 & 75 \\
4 & Running Nose & 4 & 20 \\
5 & Flu Symptoms & 8 & 40 \\
6 & Itching & 6 & 30 \\
7 & Allergy & 8 & 25 \\
8 & Cough & 4 & 40 \\
9 & Fatigue & 4 & 20 \\
10 & Difficulties in concentrating & 5 & 20 \\
\hline
\end{tabular}

Table 3 shows that there are 10 symptoms disappeared after the occupants left the building with the highest symptom is lethargy with $75 \%$ of occupant who not experiencing it after leaving the building. All the 10 symptoms achieved $20 \%$ and above of occupants who are not experiencing the symptoms after leaving the office room. Ultimately, this office building is potentially considered as sick building with 10 out of 17 SBS symptoms disappeared after the occupants left the building. 


\subsection{Occupant Satisfaction}

The building's occupants were requested to give their perception regarding satisfaction level and the perceived condition of 3 parameters of IAQ that are the thermal, humidity, and air velocity. The results of occupants' perception are presented in figures 3 to 8 .

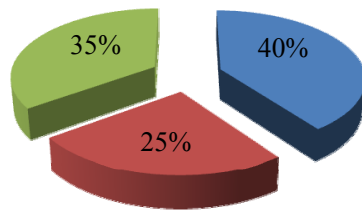

Figure 3. Satisfaction regarding temperature

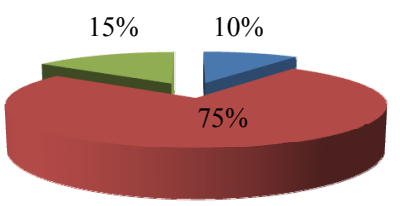

- dissatisfied

neutral

satisfied

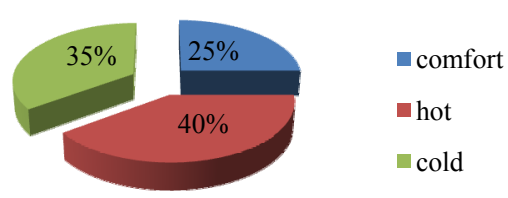

Figure 4. Perceived thermal condition

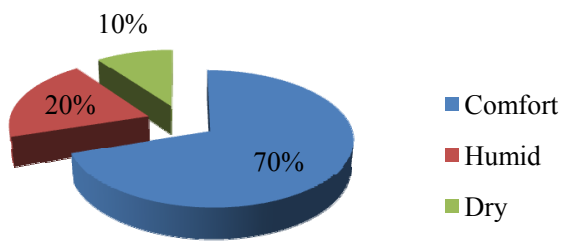

Figure 6. Perceived humidity condition

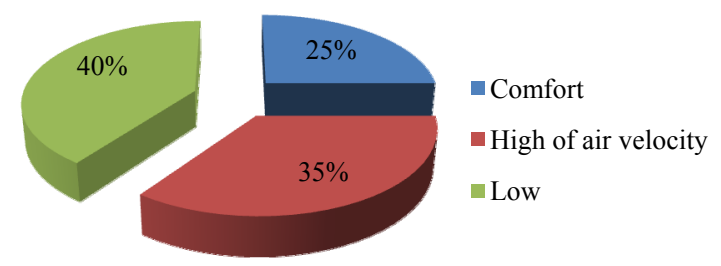

Figure 8. Perceived air velocity condition

Figure 7. Satisfaction regarding air velocity

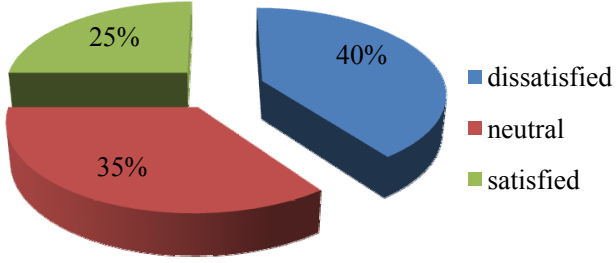

The findings revealed that $40 \%$ of building's occupants dissatisfied on thermal condition due to its hot condition. Additionally, the air velocity perceived by building's occupants is low and resulted to $40 \%$ dissatisfaction amongst the building's occupants. Subsequently, the occupants were asked whether they are able to adjust the temperature and air velocity of the air-conditioning in the office rooms. The answer for this question is presented in figures 9 and 10. 


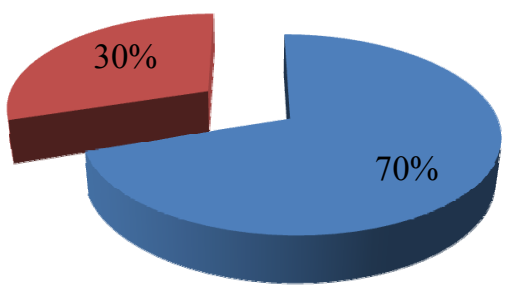

Figure 9. Ability to adjust temperature

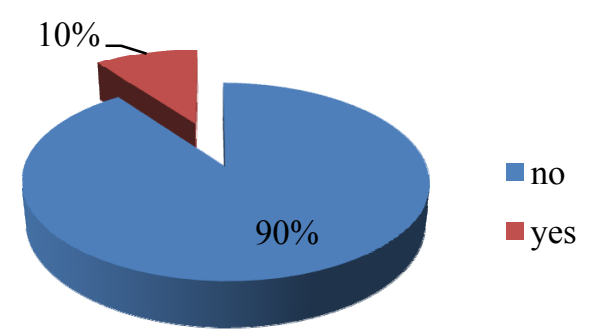

Figure 10. Ability to adjust air velocity

Most of building's occupants indicated that they are not able to adjust their indoor temperature and air velocity. This means that, if the indoor temperature and the air velocity are not suitable then it will lead to the dissatisfaction of building's occupant.

\subsection{Correlation of IAQ toward Working Performance}

In the questionnaire survey, the occupants were asked to rate based on 5-points Likert scale whether the temperature, humidity and air velocity has any interference on their working performance. The result of this assessment is in the form of correlation between IAQ with working performance as presented in table 4 .

Table 4. Correlation between factors affecting IAQ and working performance

\begin{tabular}{llllll}
\hline Correlation $(\boldsymbol{\rho})$ & Motivation & Ability & Quantity & Quality & Timeliness \\
\hline Temperature & 0.331 & 0.648 & 0.081 & 0.276 & 0.159 \\
Humidity & 0.299 & 0.244 & 0.226 & 0.146 & -0.062 \\
Air Velocity & -0.026 & 0.263 & 0.183 & 0.043 & 0.27 \\
\hline
\end{tabular}

Table 4 shows that the correlation value of temperature with the working performance varies in the range of 0.081 to 0.648 . For humidity, the correlation value varies from the -0.062 to 0.299 and for air velocity the value varies from the -0.026 to 0.27 . Since the correlated values concerned in this study are absolute in nature, the temperature correlated values are the biggest variations. This indicates that the temperature has the greatest influence on working performance as compared to humidity and air velocity.

For air temperature, the highest correlation is working ability with the value of 0.648 . This indicates that both variables are strongly correlated which means if the value of temperature decreases so do the working ability, and vice versa. However, for the lowest correlated is with the working quantity with the value of 0.081 . This is indicates that temperature has no correlation either towards increases or decreases the working quantity.

For humidity, the highest correlation value is with the working motivation with the value of 0.299 which indicates that both variables are weakly correlated. However, since the lowest correlation value is with the working timeliness with the value of -0.062 , the humidity is considered has no correlation with the working timeliness.

For air velocity, the highest correlation value is with working timeliness with the value of 0.27 . This value indicates that both variables are weakly correlated. Besides, for the lowest correlation value was resulted by its correlation with working motivation and working quality with the value of -0.026 and 0.043 . These are indicates that the air velocity has no correlation with these 2 variables.

\section{Conclusion}

The study on relationship between IAQ with work performance has attracted many researchers who are involved in developing guideline related to this issue. Hence, this study assessed the correlation of IAQ on working performance in office building and the findings of study can be concluded as:

Since the SBS symptoms disappeared after the occupant leaves the building then it can indicates that the office building is a sick building.

The occupant dissatisfied with IAQ in the office which are resulted either from temperature or air velocity. These are due to most of office workers are not able to adjust temperature and air velocity which are distributed 
through air-conditioning system at the office.

The results of correlation test between IAQ parameters and working performance parameters indicates that temperature is the most correlated parameter with working ability.

\section{Acknowledgements}

Thanks and gratitude to Ministry of Higher Education Malaysia and Research and Innovation Centre of Universiti Tun Hussein Onn Malaysia (UTHM) for funding this paper under Short Term Grant (STG) vote 1073 .

\section{References}

Antikainen, R., Lappalainen, S., Lönnqvist, A., Maksimainen, K., Reijula, K., \& Uusi-Rauva, K. (2008). Exploring the relationship between indoor air and productivity. Scandinavian journal of Work, Environment \& Health, 4, 79-82.

Bryman, A., \& Cramer, D. (2002). Quantitative Data Analysis with SPSS Release 10 for Windows (2nd ed.). Taylor and Francis inc.

Cohen, J. (1988). Statistical Power Analysis for The Behavioral Sciences (2nd ed.).

Daud, Z. M., Ahmad, M. H., \& Yusof, F. (2009). Elementary Statistics: Prentice Hall, Pearson (M) Sdn Bhd.

Federspiel, C., Liu, G., Lahiff, M., Faulkner, D., Dibartolomeo, D., Fisk, W., ... Sullivan, D. (2002). Worker Performance And Ventilation: Analysis Of Individual Data For Call-Center Workers. In Indoor Air 2002 Conference, pp. 1-6.

Fisk, W. J., Price, P. N., Faulker, D., Sullivan, D. P., Dibartolomeo, D. L., Federspiel, C. C., ... Lahiff, M. (2002). Worker Performance And Ventilation: Analyses Of Time-Series Data For A Group Of Call-Center Workers. In Indoor Air. Monterey, CA, June 30 - July 5.

Hansen, S. J., Burroughs, H. E., \& CIAQP. (1991). Managing Indoor Air Quality. Journal of the Institute of Heating and Ventilating Engineers (Vol. 34). London, UK: CRC Press Taylor \& Francis Group.

Israeli, E., \& Pardo, A. (2011). The sick building syndrome as a part of the autoimmune ( auto-inflammatory ) syndrome induced by adjuvants. Mod Rheumatol, 21, 235-239. http://dx.doi.org/10.1007/ s10165-010-0380-9

Jones, B. W. (2002). Capabilities and limitations of thermal models for use in thermal comfort standards. Energy and Buildings, 34(6), 653-659. http://dx.doi.org/10.1016/S0378-7788(02)00016-6

Joshi, S. M. (2008). The sick building syndrome. Indian Journal of Occupational and Environmental Medicine, 12(2), 61-64. http://dx.doi.org/10.4103/0019-5278.43262

Kamaruzzaman, S. N., \& Sabrani, N. A. (2011). The Effect of Indoor Air Quality ( IAQ ) Towards Occupants ' Psychological Performance in Office Buildings. Design + Built, 4(2001), 49-61.

Khalil, N., \& Husin, H. N. (2000). Post Occupancy Evaluation towards Indoor Environment Improvement in Malaysia 's Office Buildings. Journal of Sustainable Development, 2(1), 186-191.

Kosonen, R., \& Tan, F. (2004). The effect of perceived indoor air quality on productivity loss. Energy and Buildings, 36(10), 981-986. http://dx.doi.org/10.1016/j.enbuild.2004.06.005

Mahbob, N. S., Kamaruzzaman, S. N., Salleh, N., \& Sulaiman, R. (2011). A Correlation Studies of Indoor Environmental Quality (IEQ) Towards Productive Workplace. In 2nd International Conference on Environmental Science and Technology, 6, 434-438.

Melikov, A. K., \& Kaczmarczyk, J. (2012). Air movement and perceived air quality. Building and Environment, 47, 400-409. http://dx.doi.org/10.1016/j.buildenv.2011.06.017

Rotundo, M. (2002). Defining and Measuring Individual Level Job Performance: A Review and Integration. University of Toronto.

Sulaiman, Z., \& Mohamed, M. (2011). Indoor Air Quality and Sick Building Syndrome Study at Two Selected Libraries in Johor Bahru, Malaysia. Environment Asia, 4(1), 67-74.

Linden,V. d., Boerstra, A. C., Raue, A. C., Kurvers, A. K., S. R., \& de Dear, R. J. (2006). Adaptive temperature limits: A new guideline in The Netherlands A new approach for the assessment of building performance with respect to thermal indoor climate. Energy and Buildings, 38(1), 8-17. http://dx.doi.org/10.1016/j.enbuild.2005.02.008 
Wargocki, P., Wyon, D. P., \& Fanger, P. O. (2000). Productivity is affected by the air quality in offices. Healthy Buildings, 1, 635-640.

WHO Publications. (2009). Natural Ventilation for Infection Control in Health-Care Settings. Switzerland.

Wyon, D. P. (2004). The Effects of Indoor Air Quality on Performance, Behaviour and Productivity.

\section{Copyrights}

Copyright for this article is retained by the author(s), with first publication rights granted to the journal.

This is an open-access article distributed under the terms and conditions of the Creative Commons Attribution license (http://creativecommons.org/licenses/by/3.0/). 